\title{
Sequence analysis of the cDNA encoding for SpCTx: a lethal factor from scorpionfish venom (Scorpaena plumieri)
}

\author{
Fábio L. S. Costa', Maria Elena De Lima', Suely G. Figueiredo², Rafaela S. Ferreira', Núbia S. Prates',
}

Tetsu Sakamoto ${ }^{1}$ and Carlos E. Salas ${ }^{1 *}$ (i)

\begin{abstract}
Background: Lethal factors are multifunctional oligomeric proteins found in the venomous apparatus of Scorpaeniformes fish. These toxins elicit not only an array of biological responses in vitro but also cardiovascular disorders and strong hemolytic, nociceptive and edematogenic activities in vivo. This work describes the cloning and molecular identification of two toxin subunits, denominated Sp-CTx-a and Sp-CTx- $\beta$, from scorpionfish venom (Scorpaena plumieri).

Methods: The primary structures were deduced after cDNA amplification by PCR with primers from conserved sequences described in Scorpaeniformes toxins. Following DNA sequencing and bioinformatic analysis, the tridimensional structures of both subunits were modeled.

Results: The translated sequences (702 amino acids, each subunit) show homology with other lethal factors, while alignment between Sp-CTx-a and Sp-CTx- $\beta$ shows 54\% identity. The subunits lack N-terminal signal sequences and display masses of approximately $80 \mathrm{kDa}$ each. Both Sp-CTx subunits display a B30.2/SPRY domain at the C-terminal region with typically conserved motifs as described in these toxins. Secondary structure prediction identified six a-helices 18 residues long in both $a$ and $\beta$ subunits, some of them amphiphilic with their N-terminal flanked by many basic residues, creating a cationic site associated with the cytolytic activity of these toxins. Antimicrobial potential sites were identified in Sp-CTx and share some features with other peptides presenting variable and broad-spectrum activity. A phylogenetic tree built to represent these toxins supports the proximity between scorpionfish, lionfish and stonefish.

Conclusion: The study identified a putative toxin protein whose primary structure is similar to other fish toxins and with potential for production of antivenom against scorpionfish envenomation in Brazil. As a prelude to structure-function studies, we propose that the toxin is structurally related to pore-forming marine toxins.
\end{abstract}

Keywords: CDNA, Lethal factor, Scorpaena plumieri, Scorpionfish, Venom gland

\section{Background}

Scorpaeniformes from the families Scorpaenidae and Synanceiidae are the most venomous marine fishes known to date. Their venom apparatus encompasses dorsal, anal and pelvic fin spines associated with venom-containing tissues glands [1]. Occasional envenomation occurs by accidental poisoning by fish

\footnotetext{
* Correspondence: cesbufmg@icb.ufmg.br; cesbufmg@yahoo.com

${ }^{1}$ Departamento de Bioquímica e Imunologia, Instituto de Ciências Biológicas, Universidade Federal de Minas Gerais, Av. Antônio Carlos, 6627, Pampulha, Belo Horizonte, MG 31270-901, Brazil

Full list of author information is available at the end of the article
}

spines. Clinical and pharmacological studies suggest that active components of fish venom exhibit cytolytic (hemolytic), inflammatory, neuromuscular and pronounced cardiovascular activities [2-5].

Scorpionfish members of the genus Scorpaena inhabit shallow waters of the tropical Atlantic Coast. Scorpaena plumieri, known in Brazil as "aniquim", "mamangá" or "moréia-ati", exhibits disguising coloration that predisposes humans to poisoning along the Brazilian shore [6]. An array of symptoms including excruciating pain at the site of the puncture, edema and cardiovascular disorders are observed following envenoming [7]. 
Many of the symptoms associated with injury caused by Scorpaeniformes are attributable to multifunctional proteins, described as "lethal factors" identified in the venom. Due to their strong hemolytic activity, these proteins have been designated as cytolytic toxins or "multifunctional cytolysins" (for a review, see $[4,8]$ ). It was demonstrated that the hemolytic effect of these toxins is due to pore formation on the cell membrane of erythrocytes [9-12].

So far, cytolysins have been identified in the following groups: Pterois [13, 14], Scorpaenopsis, Sebastiscus and Sebastapistes [15] and Scorpaena [16] from the Scorpaenidae family, Hypodytes from the Tetraogidae family, Siganus fuscescens from the Siganidae family [17] and Inimicus [14] and Synanceia [18-20] from the family Synanceiidae.

The toxins are $148-160 \mathrm{kDa}$ proteins composed by two homologous subunits, designated as $\alpha$ and $\beta$, that remain associated via non-covalent interaction creating a dimeric structure. The domains MACPF/CDC (Membrane Attack Complex-Perforin/Cholesterol-Dependent Cytolysin), known for forming large, ring-shaped supramolecular oligomeric pore complexes on erythrocyte membranes, represent an ancient pore-forming superfamily $[10,19,20]$.

The cytolytic toxin (Sp-CTx) was purified from venom of the scorpionfish S. plumieri $[11,16]$. It displays vasorelaxant activity and induces disorders in the cardiovascular system by an increase in sarcolemmal $\mathrm{Ca}^{+2}$, partially caused by release of endogenous noradrenaline [21, 22]. Sp-CTx is a dimeric glycoprotein $(\approx 75 \mathrm{kDa} /$ subunit); its tryptic digestion yields peptide fragments whose Open Reading Frame (ORF) confirms its similarity to fish cytolysins $[11,16]$.

A striking property shared by fish venoms is their ability to induce hemolysis in vitro, arguing for a functional resemblance. The structural similarity between fish venoms was evident as most toxins were disabled upon reaction with horse-derived stonefish antivenom (SFAV) raised against crude venom of the stonefish Synanceia verrucosa (Commonwealth Serum Laboratories, Melbourne, Australia) [13, 14, 19, 20, 23-26]. The immune cross-reactivity among Scorpaeniformes toxins suggests that they share a common evolutionary ancestor. Based on these similarities, the design of DNA primers derived from the structure of stonefish toxin was instrumental for inferring the structure of $S$. verrucosa toxin $[19,27]$. A similar strategy was applied to determine the primary structures of toxins from lionfish, waspfish and rabbitfish $[14,17]$, barchin scorpionfish, tassled scorpionfish and false kelpfish [15].

We previously described the production and partial characterization of a cDNA library from venomous tissue of S. plumieri, by using the random sequencing approach, and generated hundreds of partial sequences
[28]. This study aims to identify the coding sequences for S. plumieri toxin, and to verify the presence of determinants attributable to the protein that could be responsible for the pharmacological effects of this toxin. To find the mRNA encoding for the lethal factor in $S$. plumieri, we have used the library or the cDNAs source of this library and primers from conserved regions of the toxin to produce the in silico full amino-acid sequence of $\alpha$ - and $\beta$-subunits of Sp-CTx. We further analyzed structural features of the hypothetic protein and the similarities with other fish venom toxins.

\section{Methods \\ Biological specimens}

Three live specimens of the scorpionfish $S$. plumieri (15-30 cm, length) were collected by a local fisherman off the Coast at Espírito Santo, Brazil and kept in an aquarium for a short duration prior to dissection. Fishing was authorized by the Instituto Brasileiro do Meio Ambiente e dos Recursos Naturais Renováveis - IBAMA (the Brazilian Public Agency for Environment Affairs). Glands tissue was dissected from the dorsal, pelvic and caudal ray-fin structures and kept in liquid $\mathrm{N}_{2}$ during homogenization in a grinder mill.

\section{cDNA library construction}

Total RNA was obtained from excised venom glands using the guanidinium isothiocyanate extraction procedure described by [29]. Poly(A) ${ }^{+}$RNA was isolated by oligo(dT)-cellulose chromatography (mRNA Isolation Kit, Agilent Technologies, Inc. USA). Five $\mu \mathrm{g}$ of RNA were transcribed into cDNA using the ZAP cDNA synthesis kit (ZAP-cDNA Gigapack III gold cloning kit, GE, USA).

\section{RT-PCR procedure}

A polymerase chain reaction was performed to amplify DNA from the excised bacteriophage library $\left(\sim 10^{6}\right.$ pfus $)$ or from the cDNA synthesized from $5 \mu \mathrm{g}$ of total RNA or $500 \mathrm{ng}$ of mRNA chromatographically purified following cDNA synthesis (GE Healthcare Life Sciences, USA), according to the manufacturer's instructions.

DNA amplification was performed using Platinum ${ }^{\circ} \mathrm{Taq}$ DNA Polymerase (Invitrogen ${ }^{\mathrm{Tw}}$, Life Technologies, Inc. USA) under the following conditions: pre-incubation at $94{ }^{\circ} \mathrm{C}$ for $5 \mathrm{~min}$; 35 cycles consisting of denaturation at $94{ }^{\circ} \mathrm{C}$ for $30 \mathrm{~s}$, annealing at $45-65{ }^{\circ} \mathrm{C}$ ( Tm depending of the primer) for $30 \mathrm{~s}$; extension at $72{ }^{\circ} \mathrm{C}$ for $1-2 \mathrm{~min}$ and final extension at $72{ }^{\circ} \mathrm{C}$ for $5 \mathrm{~min}$. Amplified products were subcloned into $\mathrm{pCR}^{\circ} 8 / \mathrm{GW} / \mathrm{TOPO}^{\circ} \mathrm{TA}$ Cloning with One Shot ${ }^{\circ}$ TOP10 E. coli kit (Invitrogen ${ }^{\text {tw }}$, Life Technologies, Inc.). The DNA of plasmid clones was isolated as described by Sambrook \& Russell [30] and used for sequencing. Each PCR fragment encoding a putative region of the toxin was 
cloned and the consensus sequence of at least 3-4 replicates assembled into the final sequence.

\section{Primer design}

Initially, primers were designed based on conserved sequences from toxins already described in other Scorpaeniform species. The nucleotide sequences of primers used in experiments are summarized in Table 1. A total of twelve primers (eight for $\alpha$-subunit and four for $\beta$-subunit) were employed to fully characterize the DNA encoding both subunits (Fig. 1). DNA primers Deg (forward and reverse) were used as described by Kiriake \& Shiomi [13] to identify lionfish toxins while remaining primers were based on toxin sequences from stonefish $[5,9,19,20]$.

Designations of the primers were based on reported DNA sequences corresponding to regions 60-83 $\left(\alpha_{\mathrm{T}}-\mathrm{f}\right)$,

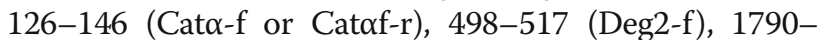
1809 (Deg-r or Degr-f) and (2151-2171) Syna-r from $\alpha$-subunit and (52-71) $\beta_{\mathrm{T}}-\mathrm{f}, 1621-1638$ (CD $\beta-\mathrm{r}$ or $\mathrm{CD} \beta \mathrm{r}$-f), and 2139-2157 (Syn $\beta$-r) from $\beta$-subunit (Fig. 1).

\section{Comparative modeling}

Comparative models of the Sp-CTx ( $\alpha$ - and $\beta$-subunits) were constructed using the Automated Mode of SWISS-MODEL server [31]. The target sequences were used for identification of templates based on Blast and HHblits. The crystal structures of stonustoxin subunits $\alpha$ (PDB ID:4WVM_A) and $\beta$ (PDB ID:4WVM_B), at $3.1 \AA$ resolution, were used for modeling of Sp-CTx subunits. The alignment between target and template sequences was conducted to generate $3 \mathrm{D}$ models. The stereochemical quality of the models was determined by Ramachandran plot assessment generated by RAMPAGE
[32]. The models were further evaluated through ProSA [33] and QMEAN statistical parameters [34]. We also calculated the RMSD values between the models and their corresponding template.

The HADDOCK 2.2 web server [35] was used for protein-protein docking of modeled structures. During the docking procedure, HADDOCK incorporated information about interacting residues at the interface of the protein complex. Therefore, before docking, contacts were identified with the InterProSurf web server [36], using template structures as an input to predict interacting residues.

\section{Sequence and analysis of clones}

Colonies grown overnight in ampicillin-supplemented medium at $37{ }^{\circ} \mathrm{C}$ were randomly selected. Plasmid DNA was isolated by the alkaline lysis method [30].

DNA sequences were obtained in the automated sequencer 3.100 Genetic Analyzer System using BigDye ${ }^{\mathrm{me}}$ Terminator v1.1, v3.1 Ready Reaction Mix (Applied Biosystems Inc., Foster City, CA, USA) in the presence of M13 forward primer or its reverse. Analysis of data was carried out using the software Phred for base calling and the quality score cutoff was set at 10 [37]. The nucleotide sequences from the vector, adaptors and Escherichia coli DNA were removed by the program VecScreen (http:// www.ncbi.nlm.nih.gov/tools/vecscreen).

Amino-acid sequences of toxin transcripts were deduced via the program Open Reading Frame (ORF) Finder (https://www.ncbi.nlm.nih.gov/orffinder/). The isoelectric point (pI) and molecular mass (MM) from derived sequences were computed by the software Swiss-Prot/TrEMBL located in Expasy.

Table 1 Nucleotide sequences of primers used for RT-PCR and cloning experiments

\begin{tabular}{|c|c|c|}
\hline Primer identification & Nucleotide sequence of primer & Nucleotide position $^{\mathrm{a}}$ \\
\hline \multicolumn{3}{|l|}{ Subunit a } \\
\hline$a_{T}-f$ & 5'-ATGTCTTCAGATTTGGTAATGCCT-3' & $60-83$ \\
\hline Cata-f & 5'-CGCAGAGAGAAACTGATCCCA-3' & $126-146$ \\
\hline Cataf-r & 5'-TGGGATCAGTTTCTCTCTGCG-3' & $126-146$ \\
\hline Deg2-f & 5'-GGGGCMAATGCYTTCTTTGT-3' & $498-517$ \\
\hline Cata-r & 5'-ATTGGCTCTCCTCTTCAGTTT-3' & $900-921$ \\
\hline Degr-f & 5'-ATTACTGGGAGGTGGAGTGG-3' & $1790-1809$ \\
\hline Deg-r & 5'-CCACTCYAMCTCCCAGTAAT-3' & $1790-1809$ \\
\hline Syna-r & 5'-TYAAAGTAATCTGASAGTTCC-3' & $2151-2171$ \\
\hline \multicolumn{3}{|l|}{ Subunit $\beta$} \\
\hline$\beta_{\text {Total }^{-} f}$ & 5'-GTTGGAGTCATGCCTTCAGAC-3' & $52-71$ \\
\hline$C D \beta-r$ & 5'-GAGCTCACAGTCATACCA-3' & $1621-1638$ \\
\hline$C D \beta r-f$ & 5'-TGGTATGACTGTGAGCTC-3' & $1621-1638$ \\
\hline $\operatorname{Syn} \beta-r$ & 5'-TAGTTAAATTGACCATT-3' & $2139-2157$ \\
\hline
\end{tabular}

${ }^{a}$ Numbering is based on nucleotide sequence from stonustoxin (Synanceia horrida), accession numbers GenBank: U36237 and U32516 [18] 


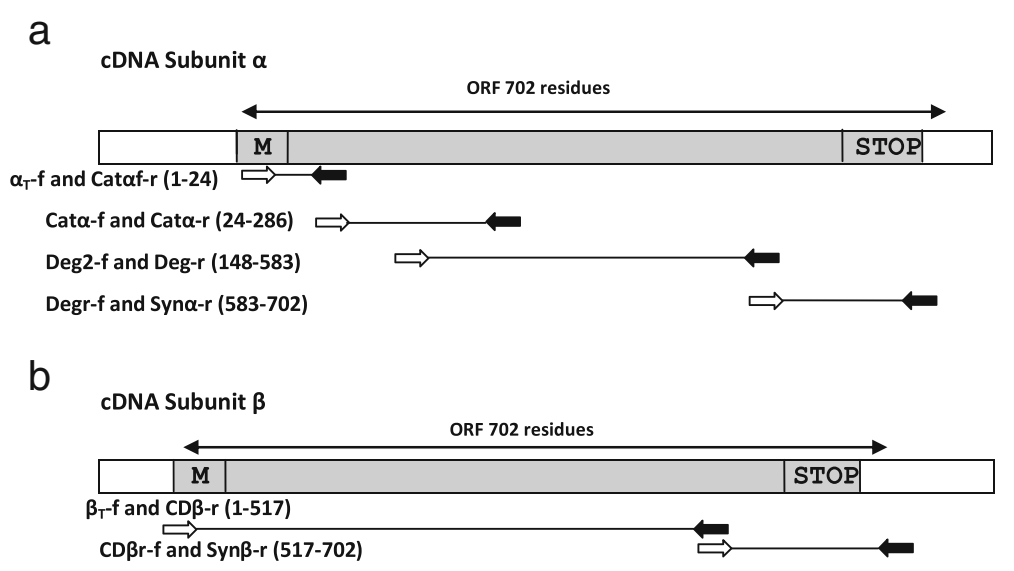

Fig. 1 Schematic cloning representation of a- and $\beta$-subunits of Sp-CTx. Forward and reverse primers are indicated by white and black arrows, respectively. The sequence of primers is shown in Table 1. Amino-acid positions are relative to the primary structures of cDNAs from Synanceia. The positions of the arrows indicate the approximate size of the putative fragment. Initiation codon (M) and stop codon (STOP). a: Union of putative fragments in a-subunit was obtained by PCRs (aT-f and Cataf-r, Cata-f and Cata-r, Deg2-f and Deg-r, Degr-f and Syna-r). b: Union of putative fragments in $\beta$-subunit ( $\beta T-f$ and $C D \beta-r$ were isolated from the $C D N A$ library and $C D \beta r-f$ and Syn $\beta$-r obtained by PCR)

The amphiphilicity, $\alpha$-helices, glycosylation sites and peptide signal sequences in Sp-CTx were analyzed by the programs PSIPRED Protein Sequence Analysis Workbench (UCL Department of Computer Science), NETNGLYC (http://www.cbs.dtu.dk/services/NetNGlyc) and SignalP 4.0 [38], respectively. Cytolytic sites in $\alpha$-helices were predicted by designing a Helical Wheel as described by Schiffer \& Edmundson [39] and using the program (http://lbqp.unb.br/NetWheels) [40].

\section{Phylogenetic analysis}

Putative orthologues of Sp-CTx were identified by submitting derived protein sequences as queries to the BLASTP algorithm [41] on the NCBI webserver (https://blast.ncbi.nlm.nih.gov/Blast.cgi) employing the non-redundant protein sequences (nr) database. From BLASTP retrieved protein accessions, we selected those accessions displaying a high similarity score with at least one of the query sequences (coverage $>80 \%$; identity $>50 \%$ ) and pertaining to one of the species known to be venomous. Sequences were submitted to MUSCLE [42] and then to the Neighbor-Joining algorithm (bootstrap replicates: 500; substitution model: Maximum Composite Likelihood), both implemented in MEGA7 [43], for sequence alignment and phylogenetic tree creation, respectively. For tree rooting analysis, we included the Stonustoxin subunit $\beta$-like protein from Clupea harengus (accession number: XP_012674574.1) and considered it an outgroup.

\section{Results}

\section{Cloning and sequencing of CDNAs encoding $\alpha-$ and $\beta$ - subunits of Sp-CTx}

Initially, we designed the set of primers $\left(\mathrm{Cat}_{\mathrm{f}-\mathrm{r}}\right)$ coding for the region containing many cationic residues apparently involved in the hemolytic activity in Scorpaeniformes [44]. Using Cat $\alpha$ primers (Fig. 1a) and cDNA $S$. plumieri as the template, a PCR fragment of approximately 800 bp was amplified and cloned into pCR8/ GW/TOPO. The sequenced fragment contained an ORF encoding 265 amino-acid residues that aligned between positions 24-286 with $\alpha$-subunits in Scorpaeniform toxins found at the NCBI databank.

To characterize the N-terminal region, a reverse complement of Cat $\alpha$ primer was designed and combined with $\alpha_{\mathrm{T}}$-f primer to produce an amplicon of $100 \mathrm{bp}$. After cloning and sequencing, this fragment generated an ORF of 24 residues corresponding to the $\mathrm{N}$-terminal of the Sp-CTx $\alpha$-subunit.

The C-terminal of Sp-CTx- $\alpha$ was identified when combining the complement of a Degr primer with Syn $\alpha-\mathrm{r}$ primer to yield a $400 \mathrm{bp}$ fragment (Fig. 1a). After cloning and sequencing, a 126-amino-acid fragment was identified and aligned to positions 583-584 of subunit- $\alpha$ from fish toxins. In this fragment we identified three termination codons (TAA) in frame, at the end of the sequence.

The identification of Sp-CTx- $\beta$ followed PCR of the excised library with primers $\beta_{\mathrm{T}}-\mathrm{f}$ and $\mathrm{CD} \beta$-r (Fig. 1b). After subcloning and sequencing, a 1545 bp PCR product yielded an ORF encoding a 515-amino-acid polypeptide sharing $81 \%$ identity with $\beta$-subunit of Pterois. To determine the $\mathrm{C}$-terminal portion of $\mathrm{Sp}-\mathrm{CTx}-\beta$, a complement of $\mathrm{CD} \beta \mathrm{r}-\mathrm{f}$ primer was designed and combined with Syn $\beta-r$ primer in PCRs using a cDNA template from S. plumieri (Fig. 1b). The resulting $600 \mathrm{bp}$ fragment was cloned; and its sequence identified an ORF of $555 \mathrm{bp}$ corresponding to 185 amino-acid residues located at $\mathrm{C}$-terminals in $\beta$-subunits. 
Several primers were designed to attempt identification of the internal regions of Sp-CTx- $\alpha$ and $\beta$ under different PCR conditions (data not shown); one of them (Deg2-f, Deg-r) produced an amplicon of $1500 \mathrm{bp}$ that was cloned and sequenced. Two related sequences were identified that aligned with internal regions of Sp-CTx- $\alpha$ (1,365 bp - 455 residues) and Sp-CTx- $\beta$ (1,104 bp - 368 residues). Assemblage of overlapping fragments produced the entire sequence from Sp-CTx- $\alpha$ and Sp-CTx- $\beta$ as expected for Scorpaeniformes toxins.

\section{Nucleotide sequence of $\alpha$ - and $\beta$-subunits of Sp-CTx}

Figure $2 \mathrm{a}$ shows the assembled $\mathrm{Sp}-\mathrm{CTx}-\alpha$ sequence containing $2192 \mathrm{bp}$. The $5^{\prime}$-untranslated region of this sequence contains the initiation codon located at position 78 , followed by an ORF encompassing 2106 bp encoding 702 amino-acid residues in frame with three stop codons in tandem, comprising the beginning of the poly A tail at the 3 '-untranslated region. In this sequence the initial ATG (Met) is followed by two Ser, and the last two amino acids before the stop codons (TAA) are Leu.

In Sp-CTx- $\beta$, the initial ATG codon was found in position 72, followed by an ORF containing 2106 bp (Fig. 2b). The initial coding ATG is followed by Pro and Ser; the 3'-terminal contains GGC-GAA (Gly-Glu) before the single stop codon (TAA). However, the poly A tail was not identified in the $3{ }^{\prime}$-untranslated region. No signal peptides were identified in the $\mathrm{N}$-terminal regions of Sp-CTx- $\alpha$ or Sp-CTx- $\beta$.

The sequences of Sp-CTx subunits were deposited in the EMBL Nucleotide Sequence Database (DDBJ/EMBL/ GenBank nucleotide sequence databases) under the following accession numbers: Seq1 MG053103/AVI44916 for the $\alpha$-subunit and Seq2 MG53104/AVI44917 for the $\beta$-subunit of S. plumieri.

\section{Amino-acid sequence of $\alpha$ - and $\beta$-subunits of Sp-CTx}

A comparison between deduced amino-acid sequences of Sp-CTxs $\alpha$ and $\beta$ evidenced 54\% identity confirming their relatedness. Several insertions/deletions of one or two amino acids at various positions are detected in both subunits. Sp-CTx- $\alpha$ contain 7 cysteinyl residues while 11 cysteinyl are found in Sp-CTx- $\beta$, five of which (in positions 204, 374, 406, 470 and 568) are preserved in both subunits (Fig. 3). The deduced subunit- $\alpha$ has a theoretical molecular mass of $79,801 \mathrm{kDa}$ with $\mathrm{pI} 6.70$, while subunit- $\beta$ has $80,126 \mathrm{kDa}$ and $\mathrm{pI} 7.88$.

Additional file 1 shows the deduced amino-acid sequences of Sp-CTxs and their alignment with toxins from three species of scorpionfish (Sebastapistes strongia, Scorpaenopsis oxycephala and Sebastiscus marmoratus), three species of lionfish (Pterois lunulata, Pterois volitans and Pterois antennata), two species of stonefish (Synanceia verrucosa and Syanceia horrida), one species of waspfish
(Hypodytes rubripinnis) and one species of devil stinger (Inimicus japonicus). The alignment shows that 176 residues (24.5\%), out of 717 amino acids (including gaps) are conserved in all toxins.

The amino-acid identities among these toxins are summarized in Table 2. It is shown that the identities between $\beta$ subunits are somewhat stronger than for $\alpha$-subunits. A strong identity was observed between the $\alpha$-subunit in P. lunulata (99\%) and the $\alpha$-subunits from $P$. volitans and $P$. antennata. Overall, the S. plumieri toxin identities are stronger with those of scorpionfishes (Scorpaenopsis oxycephala, Sebastapistes strongia and Sebastiscus marmoratus), lionfishes (P. lunulata, P. volitans and $P$. antennata) followed by waspfish (H. rubripinnis), stonefish (S. verrucosa and S. horrida) and devil stinger (I. japonicus) toxins. The identities between Sp-CTx- $\alpha$ or $-\beta$ subunits and the corresponding counterparts listed in Table 2 show that Sp-CTx- $\beta$ shares $84 \%$ identity with toxin- $\beta$ in scorpionfish $S$. oxicephala and $83 \%$ with S. strongia; meanwhile, the identity of $\mathrm{Sp}-\mathrm{CTx}-\alpha$ is $67 \%$ with $\alpha$-subunit from S. oxicephala and $66 \%$ with $\alpha$-subunit from $S$. strongia. The identity between subunits from the same species ranks around $47-54 \%$; the latter corresponds to the identity between subunits $\alpha$ and $\beta$ in S. plumieri. Meanwhile, within the Pterois group the identities between $\alpha$ and $\beta$ subunits attain 80-82\%.

The PROSITE tool [45] revealed the presence of a B30.2/SPRY domain containing 197-198 residues at the C-terminal region on each subunit, although the amino-acid sequences within these domains are somewhat variable.

\section{Predicted cytolytic domains}

The cytolytic activity of many proteins is frequently related to the presence of amphiphilic $\alpha$-helices displaying cationic sites (basic residues) flanked by hydrophobic surfaces that induce monomer aggregates able to form pores $[44,46]$.

The prediction of secondary structures in Sp-CTxs (PSIPRED) posits the presence of five amphiphilic $\alpha$-helices with a minimum size of 20 amino-acid residues (three in $\alpha$ - and two in $\beta$-subunit). Applying the "Edmunson Wheel" diagram, some predicted helixes exhibited cytolytic potential, as the hydrophobic portion is concentrated opposite to the hydrophilic side, revealing its amphiphilicity (Fig. 4). For instance, one amphiphilic $\alpha$-helix was predicted between $\mathrm{Gln}_{266}$ and $\mathrm{Asp}_{292}$ in $\mathrm{Sp}-\mathrm{CTx}-\alpha$ and the diagram design shows the final 18 residues starting with $\mathrm{Ile}_{275}$ that supports the potential of this domain, as shown in Fig. 4a with the upper hydrophobic residues $\left(\mathrm{Leu}_{282}, \mathrm{Ile}_{275}, \mathrm{Ala}_{286}, \mathrm{Leu}_{279}\right.$ and $\mathrm{Leu}_{290}$ ). Interestingly, the $\mathrm{N}$-terminal of this helix is flanked by a region that contains basic residues $\left(\operatorname{Arg}_{270}\right.$, $\mathrm{Lys}_{271}$ and $\mathrm{His}_{273}$ ), providing the cationic site common 
a

tataatggagaacaattttttattttttccaattgtgtgcaaaaaagcagggtccgaattgcceccttgttccatcaatgtcttcagat atcataatggccggtctgggtcgacctttcacccttgggtttctgtatgatgcccgcagagagaaactgatcccaggtttctcattg

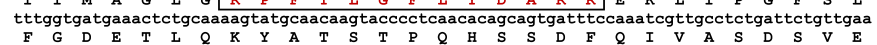
tccaagtctaacgtgatggatattgaagcttctctgggagtcagtttcctgggtggactggttgaagttgggggatctgccaaatat
$S K S$ V V

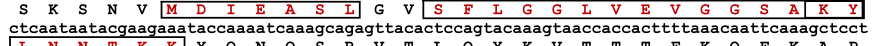

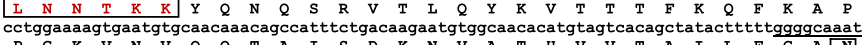
$P G K$ V N V Q Q T A I S D K N V A T H V V T A I I F G A N

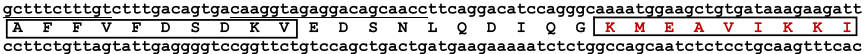
ccttctgttagtattgaggggtccggttctgtccagctgactgatgaagaaaatctctggccagcaatctctcctgcaagtttcac

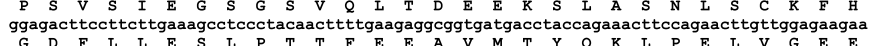
gcaagtgatggagttccaatgaaggtgtggctagtgcccttgacaagattttattctaaagctgacctgctggtccgtgacatctct $\begin{array}{lllllllllllllllll} & & \text { R } & F & Y & S & K & A & D & L & I & V & R & D & I & S\end{array}$ caaggtctagtgagaaggttcacagcatcctagaagacttgcataaactgaagaggagagccaatgattcactggaagatgacaca

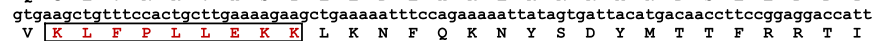

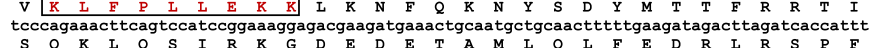
aacatcgatagtctaacatgtggatggaaatcacagagagagagatcaatgtcctcaggtcetgcattgatatcatagaggaaaca aagcacaaggctgtcttaagtcagagtcagatggtcaaggacctcettgactcagaggtaatgcatgctgtgtgctatgtcttcacc
$K$ tatgtgacagacaaggatcactacctggatgcattacgtgactacttgaaatcgccaacagtagacctgcgagagtcagaccagtg

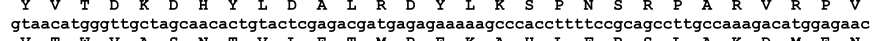
cgctgtgtccattttcttgttgcatcgattgtaaatctgaaggttgaaggtgcagccatccactactacagggagagtgtcctaata

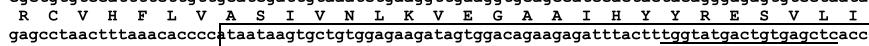
gagcctaactttaaacaccce

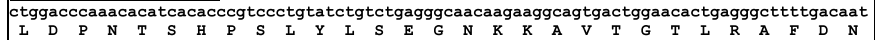
aacccagagaggttcggcctctggcagcaggtgttgtgcaacaaggggttgagtaggcgacattactgggaggtggagtggaatgga tatgttattgtcggtgttacatattcatcaattggaaggaaaaatatagacattcagagctttattgggttcagtgagacctcttgg

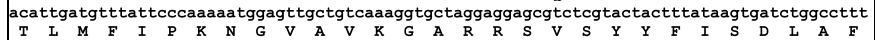

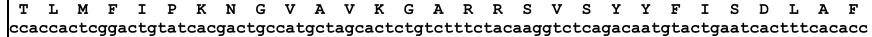

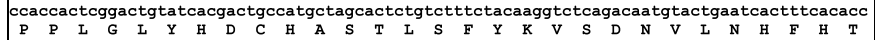

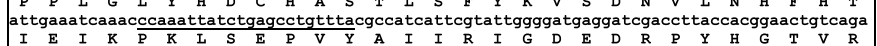

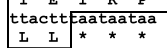

89 176 263 350 437 524 611 698 785 872 959 1,046 1,133 1,220 1,307 1,394

\section{b}

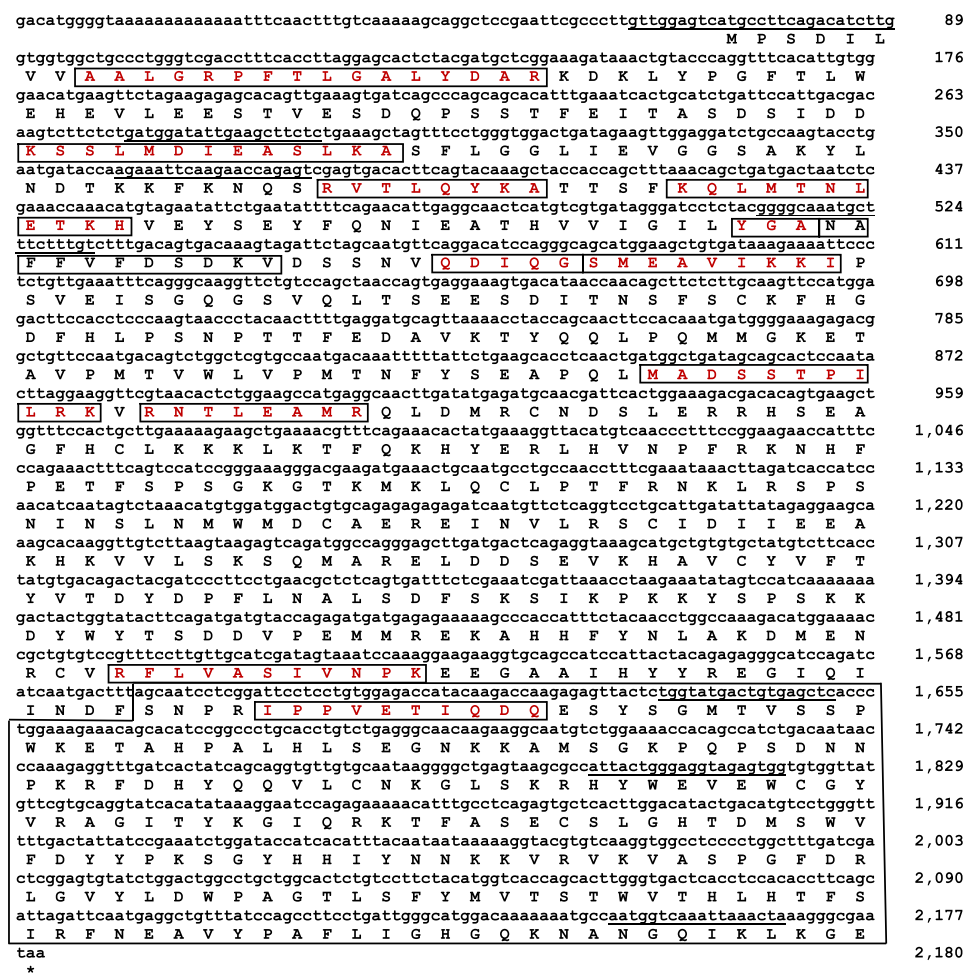

Fig. 2 (See legend on next page.) 
(See figure on previous page.)

Fig. 2 Nucleotide and deduced amino-acid sequences of cDNAs encoding Sp-CTx-a a and $\beta$-subunit $\mathbf{b}$. Single-letter amino-acid notation is used. Underlined sequences refer to primers; boxed sequences were identical to peptide sequences isolated from tryptic digestion of purified Sp-CTx toxin [11]. Stop codons in frame are indicated by asterisks. The B30.2/SPRY domain is boxed. The nucleotide sequences for $a-$ and $\beta$-subunits from S. plumieri have been deposited in the DDBJ/EMBL/GenBank nucleotide sequence databases under accession numbers 2,052,576 MG053103 and MG53104, respectively

to proteins displaying cytolytic activity. Another $\alpha$-helix with cytolytic potential was predicted between $\mathrm{Cys}_{300}$ and $\mathrm{Val}_{317}$ in $\mathrm{Sp}-\mathrm{CTx}-\beta$. The presence of amphiphilic residues $\mathrm{Ser}_{294}$ and $\mathrm{His}_{311}$ and the $\mathrm{N}$-terminal flanking residues $\mathrm{Lys}_{302}, \mathrm{Lys}_{303}$, $\mathrm{Lys}_{304}$ and $\mathrm{Lys}_{306}$ support the cytolytic feature assigned to this domain (Fig. 4b).

\section{Comparative modeling}

Using BLAST and Protein Data Bank tools, we found $55 \%$ and $68 \%$ sequence identity between $\alpha$-subunit and $\beta$-subunit of Sp-CTx and venom homologues in SNTX (S. horrida), considered sufficient to infer structural conservation (Table 2). The structure of the latter was determined by X-ray crystallography at the resolution of
3.1 $\AA$ (PDB: 4WVMA and 4WVMB, chains $\alpha$ and $\beta$ ). Despite its moderate resolution, SNTX was used as the template since it is the only structure available for this toxin in Scorpaeniformes. The automated mode of SWISS-MODEL was used for template identification, alignment and generation of the models. Using each subunit from Sp-CTx, a single model was built by the server followed by Ramachandran plot, ProSA and QMEAN analysis for model validation (Fig. 5a).

Ramachadran Plot analysis of Sp-CTx model allocated 93.2-94.5\% of amino-acid residues in favored regions, $4.2-5.8 \%$ in allowed regions and $1.0-1.3 \%$ in disallowed positions, confirming the stereochemical quality of the model. The ProSA server was used for evaluating

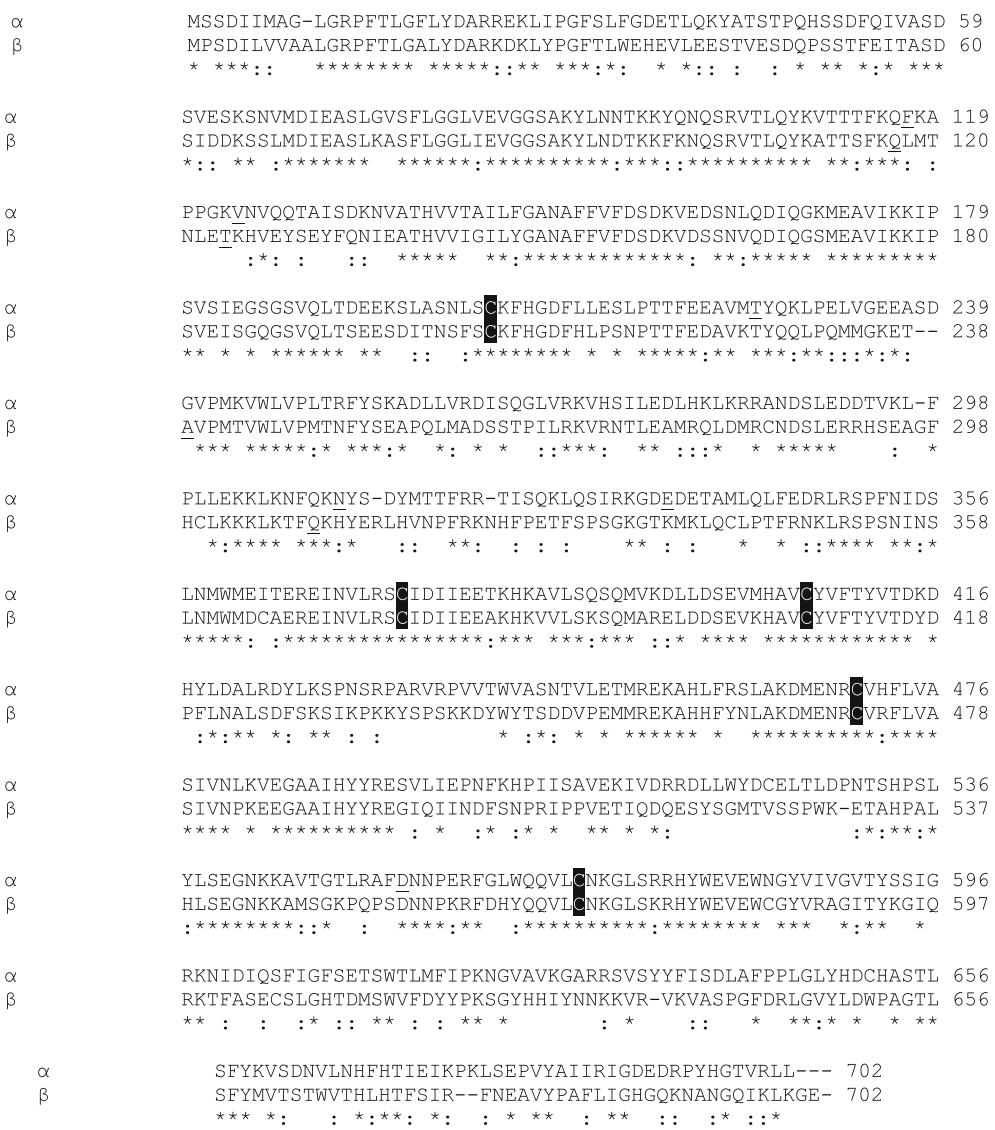

Fig. 3 Sequence alignment between Sp-CTx-a and $\beta$-subunits. Sequences were aligned using the ClustalW2 EBI. Single-letter amino-acid notation is used. Amino acids are numbered beginning at the assumed N-terminal Met for both subunits. Identical residues are shown by asterisks, whereas conservative substitutions are indicated by colons. Conserved cysteine residues are highlighted in white on a black background. An amino acid with potential for glycosylation is underlined 


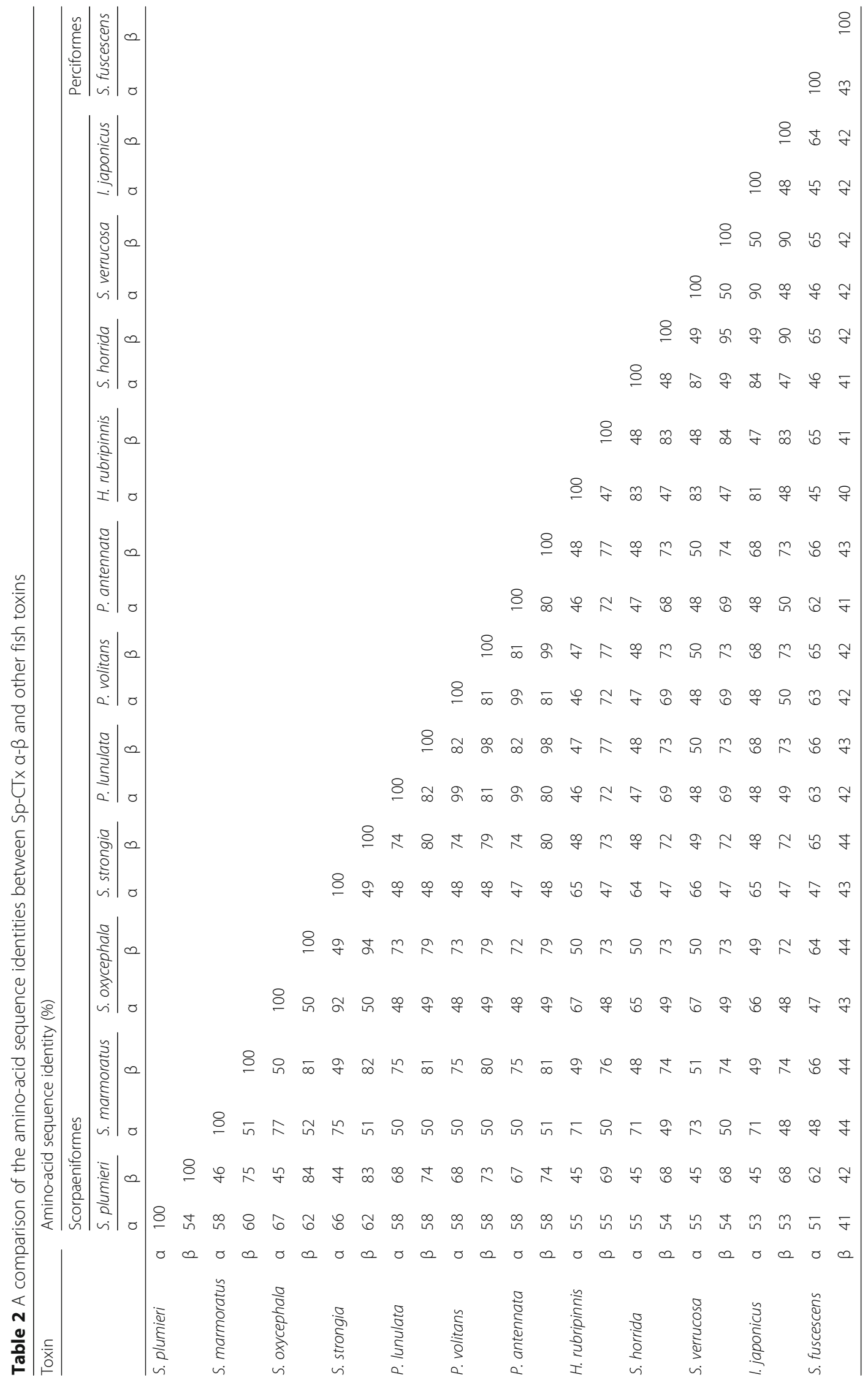




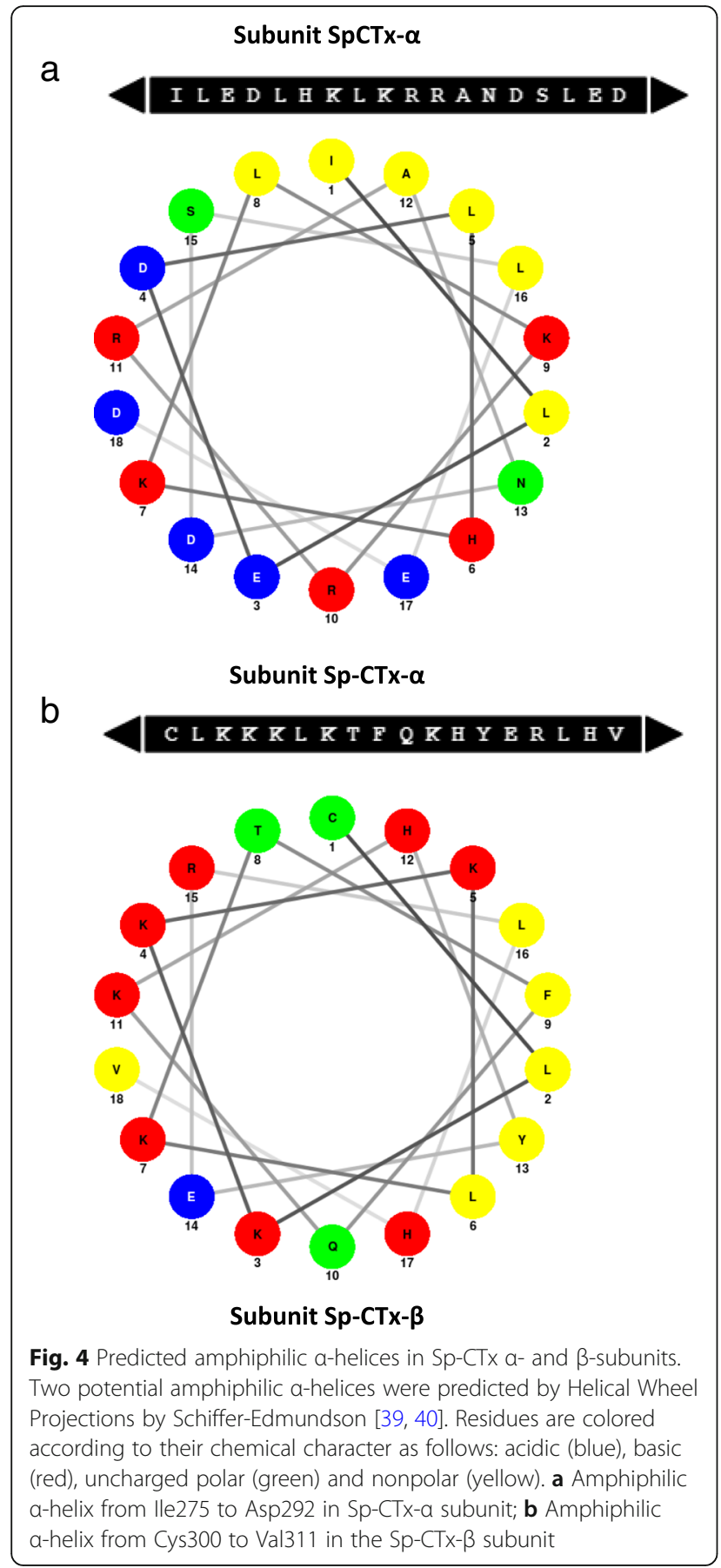

potential errors of the models. The overall quality for the Sp-CTx- $\alpha$ model, expressed as the $\mathrm{z}$-score was 11.71 , while the $\mathrm{z}$-score for the SNTX- $\alpha$ template was 9.82. The predicted $z$-score for the $\beta$-subunit was 11.85 , meanwhile the template $\mathrm{z}$-score was -10.04 . For both models ( $\alpha$ and $\beta$ ) the predicted $z$-scores for Sp-CTx are within the range observed for experimentally determined SNTX structures.
The QMEAN z-score for quality of Sp-CTx- $\alpha$ was 3.23 , and -2.57 for SNTX- $\alpha$. The QMEAN score for Sp-CTx- $\beta$ was -2.87 and for the subunit $\beta$ of the template was -2.05 . Although the $z$-scores for $\mathrm{Sp}-\mathrm{CT} \alpha \boldsymbol{\alpha}-\beta$ are far from zero, they are within the range of values calculated for the respective template. According to QMEAN, the predicted differences between the models and the crystallographic structure are mainly due to changes of torsion angles exhibiting respective z-scores of 2.94 and -2.57 for $\alpha$ - and $\beta$-subunit in Sp-CTx, while z-scores were-2.46 and-1.92 in $\alpha$ - and $\beta$-subunits from SNTX.

The modeled structures of SNTX and Sp-CTx were superimposed when RMSD in backbone atoms were $0.170 \AA$ and $0.142 \AA$, for $\alpha$ - and $\beta$-subunits, respectively (Fig. 5b). These low RMSD values highlight the extensive superposition between the model and the template with minimum deviation from backbone atoms. We then predicted the structure of the heterodimer complex composed with the modeled subunits. For that purpose, interacting interface residues were predicted at the InterProSurf web server and possible binding modes were calculated using HADDOCK. The protocol identified via rigid body docking, semi-flexible docking, and explicit solvent refinement 398 complex structures grouped into 5 clusters. According to HADDOCK protocol cluster 2 was the most reliable, encompassing 78 members and exhibiting a z-score of -1.2 (a more negative value is considered better, while remaining clusters had z-scores between -0.8 and 1.5). Each complex from cluster 2 was superposed with the crystallographic structure (PDB ID: 4WVM) and their respective RMSD calculated. The structure with the lowest RMSD (1.1 $\mathrm{A})$, calculated from the backbone atoms was selected for further analysis.

The 3D structure shows (Fig. 5a) that Sp-CTx- $\alpha$ and - $\beta$ form a dimer containing a mixture of $\alpha / \beta$ folds comprising four distinct domains: a MAPCPF/CDC domain, a focal adhesion-targeting (FAT) motif, thioredoxin (THX), and finally, the C-terminal domain containing PRYSPRY. A predicted secondary amphiphilic $\alpha$-helix is shown (red) in Fig. 4 within the FAT domain.

The interface between $\alpha$ - and $\beta$-subunits of Sp-CTx has many features contained in the SNTX- $\alpha / \beta$ heterodimer. Figure $5 \mathrm{~b}$ reveals that both toxins present strong structural similarity within each heterodimer. A highly conserved loop was found in the interface between subunits. In Sp-CTx, the $\beta 4-\alpha 6$ binding site contains a hydrophobic surface comprising TMH2, helix- $\alpha 6$ and strand- $\beta 1$, which is equivalent to MACPF and CDCs structures in SNTX, thus suggesting that this region is important for dimer formation, stability and oligomerization events (Fig. 5c, d). This analysis indicates that several noncovalent interactions stabilize the dimer interface in Sp-CTx. 


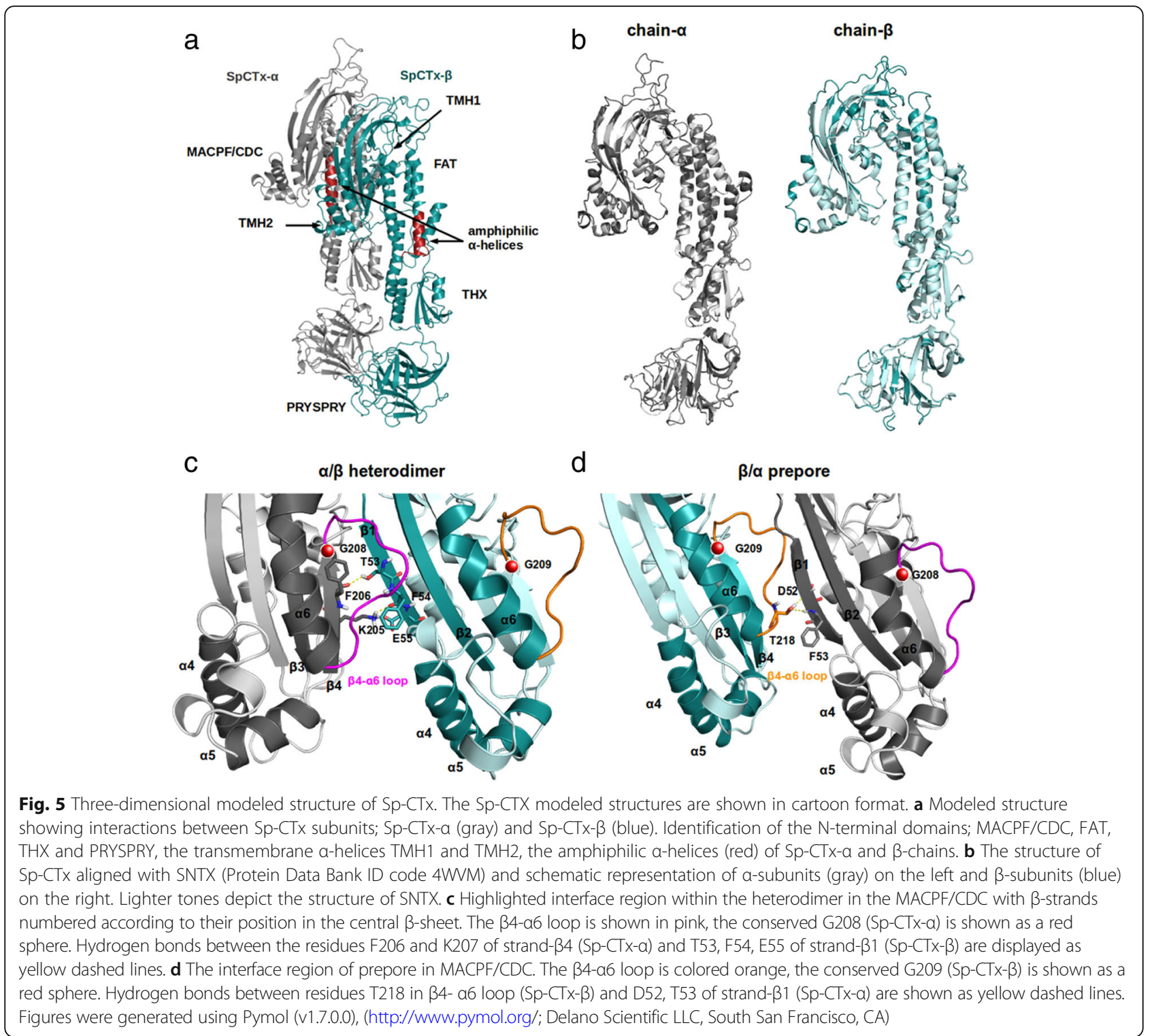

\section{Phylogenetic study of Sp-CTx}

The phylogenetic tree of Sp-CTx is shown in Fig. 6. Accordingly, toxins were grouped into three distinct clusters: i) Pterois sp. and Subunits $\beta$ group: PlTx $-\alpha, \operatorname{PaTx}-\alpha$, PvTx- $\alpha$, PlTx $-\beta$, PvTx $-\beta$ and PaTx $-\beta$ from Pterois lunulata, Pterois antennata, Pterois volitans, Pterois lunulata, Pterois volitans and Pterois antennata respectively; Subunit $\beta$ group: SmTx $-\beta$, Sp-CTx $-\beta$, SoTx $-\beta$, SsTx $-\beta$, HrTx- $\beta$, IjTx- $\beta$, NeoVTX- $\beta$ and SNTX- $\beta$ from Sebastiscus marmoratus, Scorpaena plumieri, Scorpaenopsis oxycephala, Sebastapistes strongia, Hypodytes rubripinnis, Inimicus japonicus, Synanceia verrucosa and Synanceia horrida, respectively; in addition SfTx- $\alpha$ is classified in the same cluster despite its apparent differences with other members; ii) Subunits of the $\alpha$ group: Sp-CTx- $\alpha$, SoTx- $\alpha$, SsTx- $\alpha$, SmTx- $\alpha, \operatorname{HrTx}-\alpha$, SNTX- $\alpha$, NeoVTX- $\alpha$ and IjTx- $\alpha$ from S. plumieri, Scorpaenopsis oxycephala, Sebastapistes strongia, Sebastiscus marmoratus, Hypodytes rubripinnis, Synanceia horrida, Synanceia verrucosa and Inimicus japonicus, respectively; and iii) finally, $\beta$-subunit from Perciforme Siganus fuscescens included in a separate cluster. The phylogenetic analysis suggests that genes coding for subunits from all species belong to two different clusters ( $\beta$ and $\alpha$ clades) except for Pterois, whose subunits are grouped together and branch out from the first clade.

\section{Discussion}

A pore-forming cytolysin from $S$. plumieri venom (Sp-CTx) that induces cardiovascular alterations and other pharmacological activities has been purified by $[11,16]$. Pharmacological effects similar to Sp-CTx have 


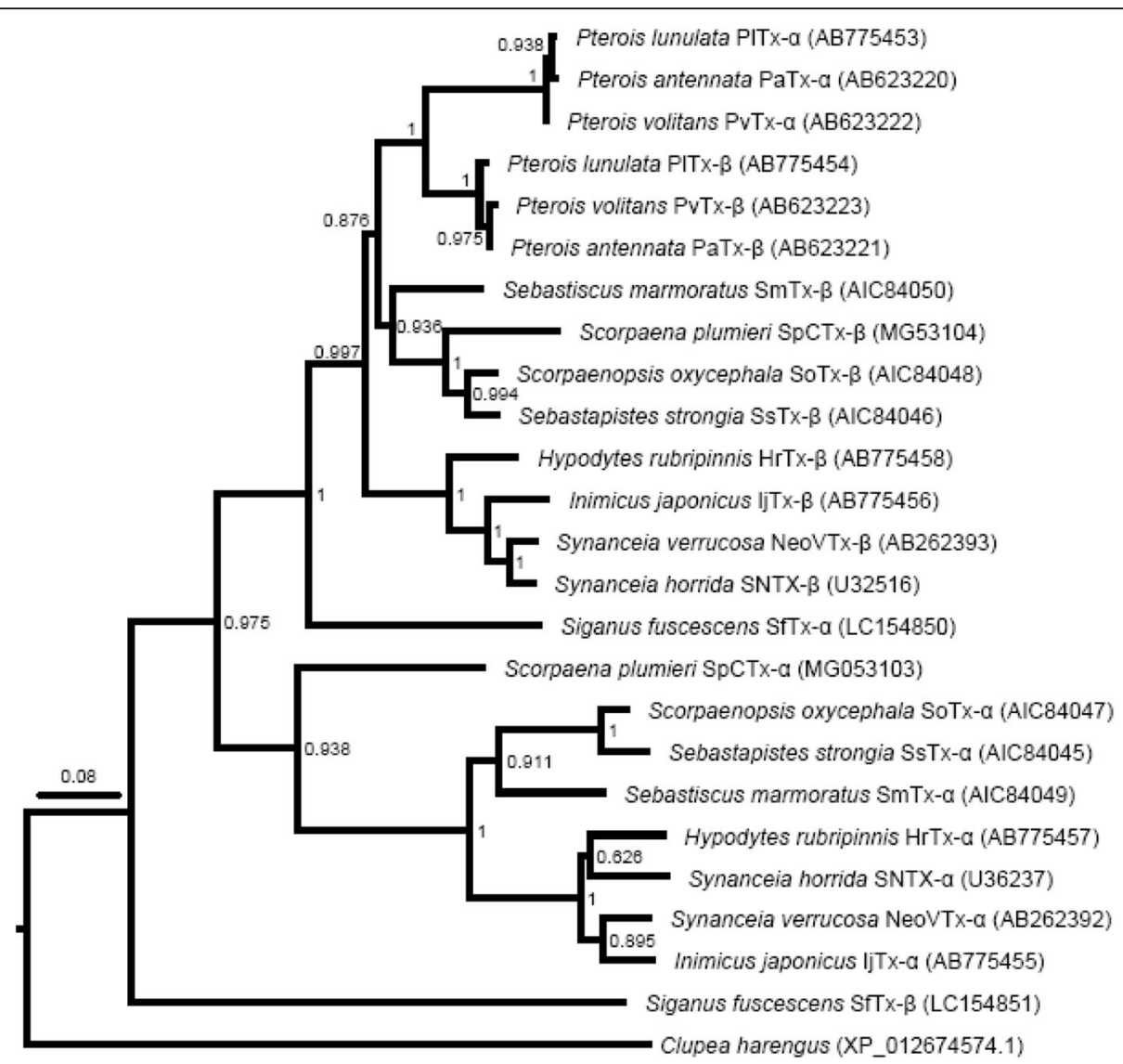

Fig. 6 Phylogenetic tree of Scorpaeniformes toxins. The tree was generated by the MUSCLE [42] and then analyzed with the Neighbor-Joining algorithm (bootstrap replicates: 500; substitution model: Maximum Composite Likelihood), both implemented in MEGA7 [43]. The selected sequences (DDBJ/EMBL/GenBank nucleotide databases) and the accession numbers are: AlC84049 and AIC84050 (Sebastiscus marmoratus), AIC84047 and AIC84048 (Scorpaenopsis oxycephala), AIC84045 and AIC84046 (Sebastapistes strongia), AB775453 and AB775454 (Pterois lunulata), AB623222 and AB623223 (Pterois volitans), AB623220 and AB623221 (Pterois antennata), AB775455 and AB775456 (Inimicus japonicus), AB775457 and AB775458 (Hypodytes rubripinnis), AB262392 and AB262393 (Synanceia verrucosa) and U36237 and U32516 (Synanceia horrida), LC154850 and LC154851 (Siganus fuscescens). As an outgroup, we included in the analysis a stonustoxin subunit beta-like protein sequence from Clupea harengus (accession number: XP_012674574.1)

been attributed to other hemolytic factors from stonefish venoms [19, 20, 47, 48]. The cardiovascular effect induced by Sp-CTx is observable both in vitro and in vivo, and includes a vasorelaxant action that appears to involve the L-arginine-nitric oxide synthase pathway [16]. It has been suggested that the cardiovascular effect of $\mathrm{Sp}-\mathrm{CTx}$ is caused by increased influx of sarcolemma $\mathrm{Ca}^{2}$ ${ }^{+}$affecting ventricular cardiomyocytes [22].

The structural features accounting for the pharmacological properties of Sp-CTx are poorly defined mainly because of the limited amounts available in fish venom [4]. To gain insight into the venom protein composition, we initially produced a cDNA library from S. plumieri to prospect by random EST the major gland components. While several lectins were identified in spine tissue, none of the readouts provided information on Sp-CTx [28].
Identification of $\mathrm{Sp}-\mathrm{CTx}$ was then attempted using the library with two primers $\left(\beta_{\mathrm{T}^{-}}-\mathrm{f}\right.$ and $\left.C D \beta-\mathrm{r}\right)$ whose sequences were derived from Scorpaeniformes toxins. The sequenced fragment annealed to $\beta$ toxins of three families already identified as lethal factors and covering $74 \%$ of the $\beta$-subunit. Attempts to recover the missing $26 \%$ region in the library were unsuccessful. Instead, the missing C-terminal complement of Sp-CTx- $\beta$ was identified in the total cDNA fraction from $S$. plumieri with $\mathrm{CD} \beta \mathrm{r}-\mathrm{f}$ primers.

For $\mathrm{Sp}-\mathrm{CTx}-\alpha$ subunit, the entire sequence was identified and assembled following amplification of four overlapping segments from the same cDNA fraction (Fig. 1). The initiators for isolation of Sp-CTx- $\alpha$ were derived from conserved nucleotide sequences reported in lionfish and stonefish toxins. The deduced sequences (Sp-CTx- $\alpha$ and Sp-CTx- $\beta$ ) from S. plumieri fulfill the 
prospects of lethal factors described in Scorpaeniformes. The deduced ORFs encode two polypeptides encompassing 702 amino-acids each and predicted mass of $80,153 \mathrm{kDa}$ for Sp-CTx- $\alpha$ and 79,816 for Sp-CTx- $\beta$. The predicted mass for $\mathrm{Sp}-\mathrm{CTx}-\alpha$ and $-\beta$ subunits resemble those of cytolysins identified in Scorpaeniformes venoms $[13-15,19,20]$.

Gomes et al. [11], estimated the size of Sp-CTx complex to be $150 \mathrm{kDa}$ based on non-reducing and denaturing electrophoretic evidence, in agreement with the figure deduced herein for $\mathrm{Sp}-\mathrm{CTx}-\alpha+$ $\mathrm{Sp}-\mathrm{CTx}-\beta$. The authors also identified internal peptides in Sp-CTx by Orbitrap-MS analysis of the trypsinized purified protein. Eight fragments totaling 79 residues (11.2\%) were identified in Sp-CTx- $\alpha$, whereas twelve fragments totaling 116 residues (16.5\%) were identified in Sp-CTx- $\beta$, matching the sequences found herein, as shown in Fig. 2a, b (fragments highlighted in boxes). A search using SignalP 4.0 tool did not detect a signal peptide-like motifs in either $\mathrm{Sp}-\mathrm{CTx}-\alpha$ or $\beta$-subunit, similarly to other Scorpaeniform toxins described to date $[19,49]$. The absence of muscular tissue in venom glands indicates that mechanical pressure is required to release the venom through the spinal system [8]. An interesting feature in Scorpaeniformes toxins is the presence of a B30.2/SPRY domain in their C-terminal regions. This domain is also found in diverse protein families, such as TRIM (Tripartite motif), RBCC (RING-finger, B-box plus coiled-coil domain), BTN (butyrophilin) and SPSB (cytokine signaling box protein) [50]. This highly variable domain possibly recognizes a specific protein ligand [51]. The functional role of B30.2 and SPRY domains is unclear, although it is evolutionarily preserved. It displays three conserved motifs, containing LDP, WEVE and LDYE $[50,52]$. The LDP motif is identifiable in Sp-CTx- $\alpha$ at position 527-529, the WEVE motif is found both in Sp-CTx- $\alpha$ and $-\beta$ at positions $578-581$ and $579-$ 582 , respectively, and the LDYE motif is absent in both subunits. On the other hand, the crystal structure of SNTX reveals that the PRYSPRY domains in the heterodimeric toxin located distally to the $\mathrm{N}$-terminal end are structurally similar to protein domains involved in innate immunity against microorganism infection. The mediation of its action by protein-protein and protein-lipid interactions on the cell surface suggests a mechanism for toxicity in SNTX [10]. A comparative structural analysis between Sp-CTx and SNTX crystals revealed the presence of three shared domains: Membrane Attack Complex-Perforin/Cholesterol-Dependent Cytolysin (MACPF/CDC), focal adhesion-targeting (FAT) and thioredoxin (THX), [10].
MACPF/CDC proteins are perforins found in diverse organisms typically composing a ring-shaped supramolecular oligomeric membrane pore complex, such as in pathogenic gram-positive bacteria and in the mammalian complement immune system [53]. This domain interacts with FAT, which has a signaling function [54], and a region structurally similar to mitochondrial thioredoxin (THX) from Saccharomyces cerevisiae. However, the THX domain is not involved in redox reactions because it lacks a catalytic site [55].

Three-dimensional modeling was necessary because the alignment of primary sequences was insufficient to analyze the spatial orientation of $\mathrm{Sp}-\mathrm{CTx}$ residues and their molecular interactions. By building the model for each subunit and obtaining the predicted heterodimer by docking, we were able to examine in detail the heterodimer interface and to identify interactions that stabilize it.

The data led us to propose that Sp-CTx also belongs to the pore-forming MACPF/CDC superfamily, sharing a common four-strand folding and a highly twisted $\beta$-sheet anchored to three small $\alpha$-helix clusters, in which two of these helical regions insert into the membrane (transmembrane hairpins TMH1 and TMH2). Interestingly, the structural folding of these domains resembles the crystallographic structures of other proteins, such as those responsible for protein-cell interactions occurring during immunological recognition [52]. Previous studies show that when pores are formed by CDCs, the monomers assemble into a prepore unit on the membrane surface and that the ensuing pore formation involves significant secondary and tertiary structural changes in TMH1 and TMH2 to penetrate the membrane as amphipathic $\beta$-hairpins [56].

Similar to stonefish toxins, Sp-CTx displays 50\% identity between its $\alpha$ - and $\beta$-subunits, while lionfish toxins are approximately $80 \%$ identical. It is unclear whether these variations in identities between subunits in stonefish and lionfish are related to species-specific functions. Because of this strong identity [19], it was proposed that SNTX genes for $\alpha$ - and $\beta$-subunits evolved separately from a common ancestor after gene duplication.

A similarity search between $\mathrm{Sp}-\mathrm{CTx}-\alpha$ or $\mathrm{Sp}-\mathrm{CTx}-\beta$ and similar annotated sequences using the NCBI database and BLAST algorithm [41] revealed significant identity only with toxins from Scorpaeniformes. Five cysteinyl residues located at similar positions in described subunits appear to be involved in protein conformation through disulfide bridges. Ghadessy and cols. [19] identified, by titration of SNTX with DTNB, five free cysteines and ten cysteines involved in intrachain disulfide bridges. However, in Sp-CTx these residues did not interact in the heterodimer model. 
Different from toxins in terrestrial animals displaying toxin isoforms encoded by more than two alleles, there is no information to indicate the number of copies in fish toxins. Chuang and Shiao, [15] suggested that gene duplication occurred in the mother species of Scorpaeniformes where they evolved into $\alpha$ and $\beta$ subunits. The authors identified an additional toxin duplication that can be found as a pseudogene in the lineage of lionfish.

Cationic residues like lysine and arginine and the hydrophobic amino acid tryptophan are essential for the cytolytic activity in toxins [44, 57]. The membrane-permeating ability of many peptides and proteins can be attributed to the presence of hydrophobic segments or amphiphilic $\alpha$-helices and $\beta$-sheets [44]. Chuang and Shiao, [15] reported 23 positively-charged amino acids and 6 conserved tryptophanyl residues in every Scorpaeniformes toxin described, a rule that is confirmed in Sp-CTx. Additional studies by site-directed mutagenesis would be useful for clarifying the role of these residues.

To investigate the evolutionary relationships among Scorpaeniformes toxins, a phylogenetic tree was constructed and is displayed in Fig. 6. The classification of Sp-CTx agrees with previous evolutionary trees involving lethal factors $[14,15,17]$. In the diagram the amino-acid sequence of Sp-CTx is closest to those of scorpionfish and lionfish toxins followed by waspfish, stonefish and devil stinger toxins. Interestingly, the phylogenetic tree is consistent with the taxonomic classification based on the morphology of the venom glands described by Russell [58] and Halstead [1] who classified Scorpaeniformes into lionfish (Pterois) with shorter spines, scorpionfish (Scorpaena) with moderate spines and stonefish (Synanceia) with longer spines and highly developed tissue glands. The calculated sequence identities are reflected in the phylogenetic tree in which Siganus fuscescens toxin branches out from members of Scorpaeniformes, especially for $\beta$-subunit [17].

\section{Conclusion}

In this study we identified the putative sequences coding for Sp-CTx, a lethal cytolysin from S. plumieri whose biochemical properties and pharmacological actions had been previously characterized. By comparative modeling with the SNTX structure, we identified potential determinants in Sp-CTx responsible for the cytolytic activity demonstrated in this toxin. The modeled Sp-CTx $\alpha-\beta$ heterodimer fits appropriately with the structure of SNTX from $S$. horrida identified by crystallography, thus supporting the notion that these proteins share similar functions.

\section{Additional file}

\begin{abstract}
Additional file 1: Alignment of the amino-acid sequences of Scorpaeniformes toxins. a-subunits of Sp-CTx, Sm-Tx, So-Tx, Ss-Tx, PI-Tx, PV-Tx, Pa-Tx, Hr-Tx, neoVTX, SNTX and Ij-Tx. $\beta$-subunits of Sp-CTx, SmTx, So-Tx, Ss-Tx, PI-Tx, Pv-Tx, Pa-Tx, Hr-Tx, neoVTX, SNTX and Ij-Tx. Single-letter amino-acid notation is used. Cysteine residues are highlighted in white on a black background. Identical residues are identified by a segment; $\left(^{*}\right)$ denotes conserved cationic residues; $(\backslash)$ denotes conserved tryptophan. Accession numbers (DDBJ/EMBL/GenBank nucleotide sequence databases): $\alpha$ - and $\beta$-subunits: Sm-Tx from Sebastiscus marmoratus toxin, AIC84049 and AIC84050; So-Tx from Scorpaenopsis oxycephala toxin, AIC84047 and AIC84048; Ss-Tx from Sebastapistes strongia toxin, AIC84045 and AIC84046; PI-Tx from Pterois lunulata toxin, $A B 775453$ and $A B 775454 ; \mathrm{PV}$-Tx from Pterois volitans toxin, AB623222 and AB623223; Pa-Tx from Pterois antennata toxin, $\mathrm{AB} 623220$ and $\mathrm{AB} 623221$; lj-Tx from Inimicus japonicus toxin, $A B 775455$ and $A B 775456 ;$ Hr-Tx from Hypodytes rubripinnis toxin, $A B 775457$ and AB775458; neoVTX from Synanceia verrucosa, AB262392 and AB262393 and SNTX from Synanceia horrida, U36237 and U32516. (DOCX $176 \mathrm{~kb}$ )
\end{abstract}

\section{Abbreviation \\ Sp-CTx: Scorpaena plumieri Cytolytic Toxin}

\section{Acknowledgements}

The authors are grateful for the technical support offered by Dr. Evanguedes Kalapothakis during DNA sequencing protocols.

\section{Funding}

This work was supported by the National Institute of Science and Technology on Toxins (INCTTOX), the Coordination for the Improvement of Higher Education Personnel (CAPES), the State of Minas Gerais Research Foundation (FAPEMIG) and the National Council for Scientific and Technological Development (CNPq). RSF holds a CNPq Research Fellowship (Bolsa de Produtividade em Pesquisa) level 2. In addition, the publication of the present work was supported in part by CAPES through Programa Editoração CAPES (edital n. 13/2016, auxílio n. 0722/2017, processo n. 88881.142062/2017-01) and CNPq through Programa Editorial CNPq/CAPES (chamada n. 26/2017, processo n. 440954/2017-7).

Availability of data and materials

All data generated or analyzed during this research are included in this published article and its supplementary information files.

\section{Authors' contributions}

FLSC conducted and analyzed the experiments. MEL, CES, SGF and RSF analyzed the data and participated in the experimental design and the elaboration of the manuscript. NSP and TS participated in the modeling studies with the toxin. All authors read and approved the final manuscript.

Ethics approval and consent to participate

Fishing of the specimens used in the present study was authorized by the Brazilian Institute of Environment and Renewable Natural Resources (IBAMA).

Consent for publication

Not applicable.

Competing interests

The authors declare that they have no competing interests.

\section{Publisher's Note}

Springer Nature remains neutral with regard to jurisdictional claims in published maps and institutional affiliations.

\section{Author details}

${ }^{1}$ Departamento de Bioquímica e Imunologia, Instituto de Ciências Biológicas, Universidade Federal de Minas Gerais, Av. Antônio Carlos, 6627, Pampulha, 
Belo Horizonte, MG 31270-901, Brazil. ²Departamento de Ciências Fisiológicas, Universidade Federal do Espírito Santo, Vitória, ES, Brazil.

\section{Received: 27 February 2018 Accepted: 3 August 2018 Published online: 29 August 2018}

\section{References}

1. Halstead BW. Dangerous marine animals: that bites, sting, shock, are nonedible. In: Dangerous marine animals. 2nd ed. USA: Cornell Maritime PressMaryland; 1980. p. 108-17.

2. Campos FV, Menezes TN, Malacarne PF, Costa FLS, Naumann GB, Gomes HL, et al. A review on the Scorpaena plumieri fish venom and its bioactive compounds. J Venom Anim Toxins incl Trop Dis. 2016;22:35. https://doi.org/ 10.1186/s40409-016-0090-7.

3. Church JE, Hodgson WC. The pharmacological activity of fish venoms. Toxicon. 2002;40(8):1083-93.

4. Figueiredo SG, Andrich F, Lima C, Lopes-Ferreira M, Haddad V Jr. Venomous fish: a brief overview. In: de Lima ME, Pimenta AMC, Martin-Eauclaire MF, Zingali R, Rochat H, editors. Animal Toxins: State of the Art. Perspectives in Health and Biotechnology. Belo Horizonte: UFMG; 2009.

5. Gwee MCE, Gopalakrishnakone P, Yuen R, Khoo HE, Low KSY. A review of stonefish venoms and toxins. Pharmacol Ther. 1994:64(3):509-28.

6. Carvalho-Filho A. Fishes: Brazilian Coast. Ed. Melro Ltda. 3rd ed. Brazil: Sao Paulo: 1999, 320p.

7. Haddad V Jr, Martins IA, Makyama HM. Injuries caused by scorpionfishes (Scorpaena plumieri Bloch, 1789 and Scorpaena brasiliensis Cuvier, 1829) in the southwestern Atlantic Ocean (Brazilian coast): epidemiologic, clinic and therapeutic aspects of 23 stings in humans. Toxicon. 2003:42(1):79-83.

8. Ziegman R, Alewood P. Bioactive components in fish venoms. Toxins. 2015; 7(5):1497-531.

9. Chen D, Kini RM, Yuen R, Khoo HE. Haemolytic activity of stonustoxin from stonefish (Synanceja horrida) venom: pore formation and the role of cationic amino acid residues. Biochem J. 1997:325(Pt 3):685-91.

10. Ellisdon AM, Reboul CF, Panjikar S, Huynh K, Oellig CA, Winter KL, et al. Stonefish toxin defines an ancient branch of the perforin-like superfamily. Proc Natl Acad Sci U S A. 2015;112(50):15360-5.

11. Gomes HL, Andrich F, Forte-Dias CL, Perales J, Teixeira-Ferreira A, Vassalo DV, et al. Molecular and biochemical characterization of a cytolysin from the Scorpaena plumier (scorpionfish) venom: evidence of pore formation on erythrocyte cell membrane. Toxicon. 2013;74:92-100.

12. Ouanounou G, Malo M, Stinnakre J, Kreger AS, Molgo J. Trachynilysin, a neurosecretory protein isolated from stonefish (Synanceia trachynis) venom, forms nonselective pores in the membrane of NG108-15 cells. J Biol Chem. 2002:277(42):39119-27.

13. Kiriake A, Shiomi K. Some properties and CDNA cloning of proteinaceous toxins from two species of lionfish (Pterois antennata and Pterois volitans). Toxicon. 2011;58(6-7):494-501.

14. Kiriake A, Suzuki $Y$, Nagashima $Y$, Shiomi K. Proteinaceous toxins from three species of scorpaeniform (lionfish Pterois lunulata, devil stinger Inimicus japonicus and waspfish Hypodytes rubripinnis): close similarity in properties and primary structures to stonefish toxins. Toxicon. 2013;70:184-93.

15. Chuang PS, Shiao JC. Toxin gene determination and evolution in scorpaenoid fish. Toxicon. 2014;88:21-33.

16. Andrich F, Carnielli JBT, Cassoli JS, Lautner RQ, Santos RAS, Pimenta AMC, et al. A potent vasoactive cytolysin isolated from Scorpaena plumieri scorpionfish venom. Toxicon. 2010;56(4):487-96.

17. Kiriake A, Ishizaki S, Nagashima Y, Shiomi K. Occurrence of a stonefish toxinlike toxin in the venom of the rabbitfish Siganus fuscescens. Toxicon. 2017; 140:139-46.

18. Garnier $P$, Goudey-Perrière F, Breton $P$, Dewulf $C$, Petek F, Perrière C. Enzymatic properties of the stonefish (Synanceia verrucosa Bloch and Schneider, 1801) venom and purification of a lethal, hypotensive and cytolytic factor. Toxicon. 1995;33(2):143-55.

19. Ghadessy FJ, Chen D, Kini RM, Chung MC, Jeyaseelan K, Khoo HE, et al. Stonustoxin is a novel lethal factor from stonefish (Synanceja horrida) venom. cDNA cloning and characterization. J Biol Chem. 1996;271(41): 25575-81.

20. Ueda A, Suzuki M, Honma T, Nagai H, Nagashima Y, Shiomi K. Purification, properties and cDNA cloning of neoverrucotoxin (neoVTX), a hemolytic lethal factor from the stonefish Synanceia verrucosa venom. Biochim Biophys Acta. 2006;1760(11):1713-22.
21. Gomes HL, Andrich F, Mauad H, Sampaio KN, De Lima ME, Figueiredo SG, et al. Cardiovascular effects of scorpionfish (Scorpaena plumieri) venom. Toxicon. 2010;55(2-3):580-9.

22. Gomes HL, Menezes TN, Malacarne PF, Roman-Campos D, Gondim AN, Cruz JS, et al. Cardiovascular effects of Sp-CTx, a cytolysin from the scorpionfish (Scorpaena plumieri) venom. Toxicon. 2016;118:141-8.

23. Shiomi K, Hosaka M, Yamanaka H, Kikuchi T. Venoms from six species of marine fish: lethal and hemolytic activities and their neutralization by commercial stonefish antivenom. Mar Biol. 1989;103(3):285-9.

24. Kreger AS. Detection of a cytolytic toxin in the venom of the stonefish (Synanceia trachynis). Toxicon. 1991;29(6):733-43.

25. Church JE, Hodgson WC. Stonefish (Synanceia spp.) antivenom neutralizes the in vitro and in vivo cardiovascular activity of soldierfish (Gymnapistes marmoratus) venom. Toxicon. 2001;39(2-3):319-24.

26. Gomes HL, Menezes TN, Carnielli JB, Andrich F, Evangelista KS, ChávezOlórtegui $C$, et al. Stonefish antivenom neutralises the inflammatory and cardiovascular effects induced by scorpionfish Scorpaena plumieri venom. Toxicon. 2011;57(7-8):992-9.

27. Garnier P, Ducancel F, Ogawa $T$, Boulain JC, Goudey-Perrière F, Perrière $C$, et al. Complete amino-acid sequence of the $\beta$-subunit of VTX from venom of the stonefish (Synanceia verrucosa) as identified from cDNA cloning experiments. Biochim Biophys Acta. 1997;1337(1):1-5.

28. Costa FLS, De Lima ME, Pimenta AC, Figueiredo SG, Kalapothakis E, Salas CE. Expressed sequence tags in venomous tissue of Scorpaena plumieri (Scorpaeniformes: Scorpaenidae). Neotrop Ichthyol. 2014;12(4):871-8.

29. Chomczynski P, Sacchi N. Single-step method of RNA isolation by acid guanidinium thiocyanate-phenol-chloroform extraction. Anal Biochem. 1987 162(1):156-9.

30. Sambrook J, Russell DW. Molecular cloning: a laboratory manual. 3rd ed New York: Cold Spring Harbor Laboratory Press; 2001.

31. Guex N, Peitsch MC, Schwede T. Automated comparative protein structure modeling with SWISS-MODEL and Swiss-PdbViewer: a historical perspective. Electrophoresis. 2009;30(S1):S162-73.

32. Lovell SC, Davis IW, Arendall WB 3rd, de Bakker PIW, Word JM, Prisant MG, et al. Structure validation by Calpha geometry: phi, psi and Cbeta deviation. Proteins. 2003:50(3):437-50.

33. Wiederstein M, Sippl MJ. ProSA-web: interactive web service for the recognition of errors in three-dimensional structures of proteins. Nucleic Acids Res. 2007;35:W407-10.

34. Benkert P, Tosatto SCE, Schomburg D. QMEAN: a comprehensive scoring function for model quality assessment. Proteins. 2008;71(1):261-77.

35. van Zundert GCP, Rodrigues JPGLM, Trellet M, Schmitz C, Kastritis PL, Karaca E, et al. The HADDOCK2.2 web server: user-friendly integrative modeling of biomolecular complexes. J Mol Biol. 2016;428(4):720-5.

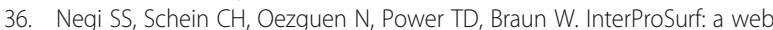
server for predicting interacting sites on protein surfaces. Bioinformatics. 2007:23(24):3397-9.

37. Ewing B, Hillier L, Wendl MC, Green P. Base-calling of automated sequencer traces using phred. I. Accuracy assessment. Genome Res. 1998:8(3):175-85.

38. Petersen TN, Brunak S, von Heijne G, Nielsen H. SignalP 4.0: discriminating signal peptides from transmembrane regions. Nat Methods. 2011;8(10):7856.

39. Schiffer M, Edmundson AB. Use of helical wheels to represent the structures of proteins and to identify segments with helical potential. Biophys J. 1967; 7(2):121-35.

40. Mól AR, Castro MS, Fontes W. NetWheels Tool: A web appication to create high quality peptide helical Wheel and net projections. 2006. http://lbqp. unb.br/NetWheels. Accessed 7 May 2018.

41. Altschul SF, Gish W, Miller W, Myers EW, Lipman DJ. Basic local alignment search tool. J Mol Biol. 1990;215(3):403-10.

42. Edgar RC. MUSCLE: multiple sequence alignment with high accuracy and high throughput. Nucleic Acids Res. 2004;32(5):1792-7.

43. Kumar S, Stecher G, Tamura K. MEGA7: molecular evolutionary genetics analysis version 7.0 for bigger datasets. Mol Biol Evol. 2016;33(7):1870-4

44. Kini RM, Evans HJ. A common cytolytic region in myotoxins, hemolysins, cardiotoxins and antibacterial peptides. Int J Pept Protein Res. 1989;34(4):277-86.

45. Hulo N, Bairoch A, Bulliard V, Cerutti L, De Castro E, Langendijk-Genevaux PS, et al. The PROSITE database. Nucleic Acids Res. 2006;34:D227-30.

46. Pasupuleti M, Schmidtchen A, Malmsten M. Antimicrobial peptides: key components of the innate immune system. Crit Rev Biotechnol. 2012; $32(2): 143-71$ 
47. Colasante C, Meunier FA, Kreger AS, Molgó J. Selective depletion of clear synaptic vesicles and enhanced quantal transmitter release at frog motor nerve endings produced by trachynilysin, a protein toxin isolated from stonefish (Synanceia trachynis) venom. Eur J Neurosci. 1996;8(10):2149-56.

48. Poh CH, Yuen R, Khoo HE, Chung M, Gwee M, Gopalakrishnakone P. Purification and partial characterization of stonustoxin (lethal factor) from Synanceia horrida venom. Comp Biochem Physiol B. 1991;99(4):793-8.

49. von Heijne $\mathrm{G}$. Transcending the impenetrable: how proteins come to terms with membranes. Biochim Biophys Acta. 1988;947(2):307-33.

50. Perfetto L, Gherardini PF, Davey NE, Diella F, Helmer-Citterich M, Cesareni G. Exploring the diversity of SPRY/B30.2-mediated interactions. Trends Biochem Sci. 2013;38(1):38-46

51. Woo JS, Imm JH, Min CK, Kim KJ, Cha SS, Oh BH. Structural and functional insights into the B30.2/SPRY domain. EMBO J. 2006;25(6):1353-63.

52. Henry J, Ribouchon MT, Offer C, Pontarotti P. B30.2-like domain proteins: a growing family. Biochem Biophys Res Commun. 1997;235(1):162-5.

53. Hadders MA, Beringer DX, Gros P. Structure of C8alpha-MACPF reveals mechanism of membrane attack in complement immune defense. Science. 2007:317(5844):1552-4

54. Hayashi I, Vuori K, Liddington RC. The focal adhesion targeting (FAT) region of focal adhesion kinase is a four-helix bundle that binds paxillin. Nat Struct Biol. 2002;9(2):101-6.

55. Bao R, Zhang Y, Zhou CZ, Chen Y. Structural and mechanistic analyses of yeast mitochondrial thioredoxin Trx3 reveal putative function of its additional cysteine residues. Biochim Biophys Acta. 2009;1794(4):716-21.

56. Hotze EM, Tweten RK. Membrane assembly of the cholesterol-dependent cytolysin pore complex. Biochim Biophys Acta. 2012;1818(4):1028-38.

57. Yew WS, Khoo HE. The role of tryptophan residues in the hemolytic activity of stonustoxin, a lethal factor from stonefish (Synanceia horrida) venom. Biochimie. 2000;82:251-7.

58. Russell FE. Marine toxins and venomous and poisonous marine animals. In: Russell FS, editor. Advances in Marine Biology, vol. 2. London: Academic; 1965.

Ready to submit your research? Choose BMC and benefit from:

- fast, convenient online submission

- thorough peer review by experienced researchers in your field

- rapid publication on acceptance

- support for research data, including large and complex data types

- gold Open Access which fosters wider collaboration and increased citations

- maximum visibility for your research: over $100 \mathrm{M}$ website views per year

At $\mathrm{BMC}$, research is always in progress.

Learn more biomedcentral.com/submissions 